\title{
Os meios de comunicação e a construção do verdadeiro no campo econômico
}

\author{
Hérica Lene 1 \\ Universidade Federal do Rio de Janeiro \\ hericalene@yahoo.com.br
}

\begin{abstract}
Resumo: Este artigo tem como objetivo articular a construção do verdadeiro no campo econômico e os discursos dos meios de comunicação sobre esta área. A questão que nos instiga é: como as notícias ajudam a construir uma "realidade" sobre o campo econômico? Partimos da premissa de que o noticiário de economia se pauta, principalmente, pelos prognósticos e não apenas pelos relatos de acontecimentos do presente. Com isso, muitas vezes, antecipam situações e provocam mudanças no mercado. $O$ corpus de análise será constituído por edições do jornal O Globo de julho de 1994, mês de lançamento do Plano Real, em vigor há 11 anos. A partir das reflexões sobre a questão da comunicação e do discurso de Mikhail Bakhtin e de Michel Foucault e de outros aportes teóricos, tentaremos analisar alguns aspectos dos discursos dos meios de comunicação na cobertura jornalística de economia.
\end{abstract}

Palavras-chave: Comunicação, poder, jornalismo econômico

Abstract: The objective this article is articulate the construction of the true in the economic field and the media speeches on this area. The question that in instigates them is: how the news helping to construct a "reality" on the economic field? It has the premise of that the economy reporter has guideline, mainly, for prognostics and not only the stories of the events of the present. With this, many times, he anticipates situations and provokes changes in the market. The analysis corpus is constituted by editions of the newspaper O Globo of July of 1994, when the Real Plan started. It is in vigour has 11 years. This article has like base the reflections about the question of the communication and the speech of Mikhail Bakhtin and Michel Foucault and others authores. We going to try to analyze some aspects of the medias speeches in the journalistic covering of the economy.

\footnotetext{
${ }^{1}$ Doutoranda em Comunicação e Cultura pela UFRJ, mestre em Comunicação pela UFF e especialista em Comunicação Organizacional pela Faculdade Cândido Mendes de Vitória. Professora do curso de Comunicação Social da Faesa (ES).
} 
Keywords: Communication, power, economic journalism

Résumé: Cet article a comme objectif articuler la construction des vrai dans du champ économique et discours des moyens de communication sur ce secteur. La question qui nous incite est: comment les observations aident à construire une "réalité" sur le champ économique? Nous partons de la prémisse dont le journal télévisé d'économie si orientation, principalement, par les pronostics et non seulement par les histoires d'événements du cadeau. Avec cela, beaucoup de fois, prévoient des situations et provoquent des changements dans le marché. Le corpus d'analyse sera constitué par des éditions du journal O Globo de juillet 1994, mois de lancement du Plan Réel (Plano Real), en vigueur a 11 ans. À partir des réflexions sur la question de la communication et du discours de Mikhail Bakhtin et de Michel Foucault et d'autres tu accostes théoriques, essayerons d'analyser quelques aspects des discours des moyens de communication dans la couverture journalistique d'économie.

Mots-clef: Communication, pouvoir, journalisme économique

Resumen: Este artículo tiene como objetivo para articular la construcción de verdad en el campo económico y los discursos de los medios en esta área. La pregunta que adentro les instiga es: ¿cómo las noticias ayudam a construir una realidad en el campo económico? Partimos de la premisa que el noticiaro de la economía si pauta, principalmente, para los pronósticos y no solamente para las historias de los acontecimientos del presente. Con esto, muchas veces, anticipan situaciones y provocan cambios en el mercado. El corpus del análisis será constituido por las ediciones del periódico O Globo de julio de 1994, el mes del principio del Plano Real, en vigor tiene 11 años. De las reflexiones sobre la cuestión de la comunicación y del discurso de Mikhail Bakhtin y de Michel Foucault y otros authores, intentaremos analizar algunos aspectos de los discursos de los medias en la cubierta periodística de la economía.

Palabras-clave: Comunicación, poder, periodismo económico 


\section{Introdução}

O campo econômico ganha cada vez mais força entre as esferas sociais na contemporaneidade. No linguajar convencional, a era atual da história é geralmente caracterizada como sendo de globalização, revolução tecnológica e democratização (Mcchesney, 2003). Nestas três áreas, a mídia e as comunicações têm um papel central no interior de uma cultura pública que é profundamente influenciada pela nova economia política.

Em termos públicos, o fenômeno recebe o nome de globalização ${ }^{2}$, mas politicamente coincide com a ideologia do neoliberalismo, uma plataforma econômico-político-social-cultural empenhada em governo mínimo, fundamentalismo de mercado, individualismo econômico e autoritarismo moral. De um modo geral, livre trânsito de commodities e a velocidade circulatória dos capitais especulativos são valores excelsos da nova economia (Sodré, 2002).

E sem um sistema comercial de mídia global, a globalização econômica e cultural seria impossível para promover os mercados globais e encorajar os valores do consumo (Mcchesney, ibid., p. 217).

Assim, as corporações de mídia e entretenimento exercem um papel estratégico. Atuam como agentes operacionais da globalização, do ponto de vista da enunciação discursiva. Não apenas legitimam o ideário global, mas o transforma no

\footnotetext{
${ }^{2}$ Foi no final do século XX que esse processo se consolidou, com a queda de barreiras alfandegárias entre os países e a revolução tecnológica, em particular no campo da informação (telefonia, televisão e computador). Essa "revolução" de base microeletrônica criou as condições físicas para um maior e instantâneo intercâmbio entre as economias e Estados nacionais. Barateou a produção, o processamento e a transmissão do conhecimento. Combinada com a desordem monetária, que começou como circunstancial, mas integrou-se ao sistema, deu origem ao aspecto mais visível da globalização no plano econômico: a autonomia do mercado financeiro em relação ao Estado-nação e entidades supranacionais, como o Fundo Monetário Internacional (FMI) ou a União Européia, e a sua volatilidade. A combinação desses fatores provocou drásticas mudanças no processo produtivo, liderado por empresas transnacionais, e, sobretudo, na forma como são feitos os investimentos mundiais. As grandes empresas se organizaram mediante fusões e parcerias e ampliaram seu poderio econômico. Seu poder de investimento inverte a relação entre governo e iniciativa privada. Nas décadas de 1970 e 1980, era o governo que ditava as regras do desenvolvimento econômico e, com base nelas, as empresas definiam as estratégias de investimentos. Atualmente, essa ordem é inversa. O Estado não consegue mais deter a movimentação do capital estrangeiro. Há cada vez menos recursos para aplicar em setores como saúde, educação e saneamento. Ele passa a se retirar de negócios como a geração de energia, a distribuição de água, o tratamento de esgoto, a coleta de lixo e as telecomunicações.
} 
discurso social hegemônico, propagando visões de mundo e de modos de vida que transferem para o mercado a regulação das demandas coletivas (Moraes, 2003).

A retórica da globalização intenta incutir a convicção de que a fonte primeira de expressão cultural se mede pelo nível do consumo dos indivíduos. Como se o mercado pudesse aglutinar o que se convencionou chamar de organização societária (Moraes, 2003, p. 186).

A chamada grande mídia, na visão de autores como Kucinski (2000), Sodré (2002) e Moraes (2003), fabrica o consenso sobre a superioridade das economias abertas, insistindo que não há saída fora dos pressupostos neoliberais.

Refletir sobre este contexto nos leva a uma proposta instigante: pensar sobre como a mídia atua como um agente discursivo deste sistema econômico. Assim, este artigo tem como objetivo articular a construção do verdadeiro no campo econômico e os discursos dos meios de comunicação sobre esta área.

A questão central que se coloca é: como as notícias ajudam a construir uma "realidade" sobre o campo econômico? Partimos da premissa de que o noticiário econômico se pauta, principalmente, pelos prognósticos e não apenas pelos relatos de acontecimentos do presente. Com isso, muitas vezes, antecipam situações e provocam mudanças no mercado.

A cobertura do campo econômico pelos meios de comunicação - o jornalismo econômico - é, portanto, nosso objeto de estudo central nesta análises, que tem como corpus edições do jornal $O$ Globo de julho de 1994, mês de lançamento do Plano Real, o último a ser adotado no país e que está em vigor há 11 anos.

O recorte para a presente análise se justifica pelo fato de que uma abordagem sobre um acontecimento importante no país, como o lançamento de um

$3 \mathrm{O}$ tema faz parte da pesquisa que estou desenvolvendo no programa de Pós-Graduação em Comunicação e Cultura da UFRJ sobre a imprensa no Brasil nas duas últimas décadas do século XX. O objetivo é compreender o processo de mudanças pelo qual passou o jornalismo nesse período e como contribuiu para a construção dos discursos em torno da nação que se reinventa na Nova República. A proposta é estudar a atuação da imprensa nessa fase tomando como objeto o jornalismo econômico. Será analisado também o surgimento de "jornalistaspersonalidades" na cobertura de economia. 
pacote de medidas econômicas, nos forneceria dados sobre a cobertura jornalística dessa área. 4

A partir das reflexões sobre a questão da comunicação e do discurso de autores como Mikhail Bakhtin (1995; 1997) e Michel Foucault (2001; 2005) e de outros aportes teóricos, tentaremos analisar alguns aspectos dos discursos produzidos pelos meios de comunicação na cobertura jornalística de economia ${ }^{5}$.

\section{A comunicação e a construção do social}

O primeiro passo para a reflexão que este artigo propõe é pensar a questão da construção do verdadeiro pelos meios de comunicação. Como as verdades são construídas? Qual o papel da linguagem nesse sentido?

A construção da verdade passa pela linguagem, que fornece os termos pelos quais o mundo passa a ser conhecido. Sistemas de valores, conceitos e mesmo noções aparentemente simples sobre as coisas e fatos do dia-a-dia se tornam a base do sistema sobre o qual os vários discursos - como o social, o político, o econômico e o cultural - são construídos.

E a constituição da palavra e o seu uso estão associados a poder, que produz realidade; produz campos de objetos e rituais da verdade. "E a palavra, a linguagem, é alvo do exercício de poderes que a controlam; os poderes não incidem apenas sobre o corpos, mas também sobre as palavras" (Foucault, 2005) .

Os rituais de verdade são, segundo Foucault, a forma mais superficial e mais visível dos sistemas complexos de restrição dos discursos. A troca e a comunicação são figuras positivas que atuam no interior desses sistemas.

\footnotetext{
4 A opção pelas edições com enfoque no Plano Real neste artigo se deu pelo fato de este pacote fazer parte do enquadramento de análise da pesquisa que desenvolvo no doutorado. $\mathrm{O}$ enquadramento será composto por acontecimentos marcantes no cenário econômico: os oito planos antiinflacionários de grande alcance, que do início do regime civil, em 1985, até o final o século passado, mudaram a moeda ou as relações de ordem econômica. Foram eles: Cruzado I (fevereiro/1986), Cruzado II(novembro/1986), Bresser (junho/1987), Verão I (janeiro/1989), Verão II (maio/1989), Collor I (março/1990), Collor II (janeiro/1991), Transição para o Real (agosto/1993) e Real (julho/1994).

5 Esse tipo de cobertura tem uma larga tradição no Brasil e vai se consolidar ao longo do século XX. Os veículos de comunicação voltados para a indústria, o comércio e os negócios de maneira geral surgem em todo o país desde meados do século XIX. Pioneiro neste sentido é o Jornal do Commercio, fundado em 1827, no Rio de Janeiro, e que se mantém até hoje em circulação, apesar de sua baixa difusão e crises freqüentes (Sodré, 1999; Barbosa, 2000).
} 
O ritual define a qualificação que devem possuir os indivíduos que falam (e que, no jogo de um diálogo, da interrogação, da recitação, devem ocupar determinada posição e formular determinado tipo de enunciados). Define também os gestos, os comportamentos, as circunstâncias, e todo o conjunto de signos que devem acompanhar o discurso; fixa, enfim, a eficácia suposta ou imposta das palavras, seu efeito sobre aqueles aos quais se dirigem, os limites de seu valor de coerção (Foucault, 2001).

Os discursos religiosos, judiciários, terapêuticos e, em parte também, os políticos não podem ser dissociados dessa prática de um ritual que determina para os sujeitos que falam, ao mesmo tempo, propriedades singulares e papéis preestabelecidos (ibid., p.38-39).

A construção dos discursos, o uso da palavra e, em consequiência, a construção de verdades estão relacionados, portanto, com o poder. "O discurso não é simplesmente aquilo que traduz as lutas ou os sistemas de dominação, mas aquilo por que, pelo que se luta, o poder do qual nos queremos apoderar" (ibid., p. 10). "Nada mais é do que a reverberação de uma verdade nascendo diante de seus próprios olhos" (ibid., p. 49).

E os meios de comunicação, como emissores essenciais de discursos sobre e para a sociedade, contribuem para a construção de verdades. Com relação a este ponto, Thompson (2002, p. 38-39) desenvolve uma abordagem interessante que contribui para a discussão proposta aqui. Ele trata da mídia na modernidade e diz que o desenvolvimento de novos meios de comunicação afetou as maneiras pelas quais os indivíduos experimentam as características de espaço e tempo da vida social. Isso fez surgir a "historicidade mediada", nosso sentido do passado e de como ele nos alcança se torna cada vez mais dependente da expansão crescente de um reservatório de formas simbólicas mediadas.

Nesse processo, surgiu a mundanidade mediada, que significa que nossa compreensão do mundo fora do alcance de nossa experiência pessoal e, de nosso lugar dentro dele, está sendo modelada cada vez mais pela mediação de formas simbólicas. Ao alterar a compreensão do lugar e do passado, o desenvolvimento dos meios de comunicação modificou o sentido de pertencimento dos indivíduos, a compreensão dos grupos e das comunidades a que eles sentem pertencer, fenômeno chamado de socialidade mediada (Thompson, 2002). 
Dessa forma, a mídia se envolve ativamente na construção do mundo social. Ao levar imagens e as informações para indivíduos situados nos mais distantes contextos, a mídia modela e influencia o curso dos acontecimentos, cria acontecimentos que poderiam não ter existido em sua ausência (ibid., p. 102).

O desenvolvimento da mídia ajudou a criar um mundo em que os campos de interação podem ser tornar globais em escala e em alcance e o passo da transformação social pode ser acelerado pela velocidade dos fluxos de informação.

E o crescimento de múltiplos canais de comunicação e informação contribuiu significativamente para a complexidade e imprevisibilidade de um mundo já extremamente complexo e para a criação de novos regimes de visibilidade dentro da sociedade. ${ }^{6}$

\section{Narrativa e discursos na cobertura jornalística}

Analisar como as notícias ajudam a construir a realidade ou verdades sobre o campo econômico requer uma verificação das vozes que aparecem nesse noticiário. Para isso, neste artigo, foram analisadas as edições do jornal $O \mathrm{Globo}^{7}$ do mês de

\footnotetext{
${ }^{6}$ Foucault não discutiu diretamente a natureza da mídia e seu impacto nas sociedades modernas, mas é interessante citá-lo neste momento como referência porque ele desenvolveu, em Vigiar e Punir e em outros lugares, um argumento diferente sobre a organização do poder nas sociedades modernas e a mudança na relação entre poder e visibilidade. $\mathrm{O}$ argumento é que as sociedades do mundo antigo e do ancien régime eram sociedades de espetáculo: o exercício do poder estava ligado à manifestação pública de força e superioridade do soberano. Era um regime de poder no qual uns poucos se tornavam visíveis a muitos, e no qual a visibilidade de poucos era usada como meio de exercer o poder sobre muitos - de tal maneira, por exemplo, que a execução pública numa praça de mercado se tornava um espetáculo no qual o poder soberano se vingava, reafirmando a glória do rei através da destruição de um súdito rebelde. Mas a partir do século XVI em diante, a manifestação espetacular de poder cedeu lugar a novas formas de disciplina e controle que foram se infiltrando nas diferentes esferas da vida. O exército, a escola, a prisão, o hospital: estas e outras instituições empregaram de forma crescente os mecanismos mais sutis de poder baseados no treinamento, na disciplina, na observação e no registro. A propagação destes mecanismos gradualmente fez surgir um novo tipo de "sociedade disciplinar" em que a visibilidade de poucos diante de muitos foi substituída pela visibilidade de muitos diante de poucos, e na qual a manifestação espetacular do poder soberano foi substituída pelo poder do olhar.

7 Lançado em 29 de julho de 1925, o jornal $O$ Globo é a primeira empresa das Organizações Globo. As notícias econômicas ocupam uma média de quatro páginas. A manchete dessa editoria é em geral macroeconômica e há preocupação com a economia do Rio de Janeiro. É uma publicação atenta em conquistar leitores com assuntos de interesse do consumidor. Nas segundas-feiras, traz uma página com os títulos "Em defesa do consumidor" ou "Indicadores financeiros". O espaço de opinião se resume a colunas (como a da jornalista Miriam Leitão).
} 
julho de 1994 que tratam do Plano Real. No total, são 22 edições. O enfoque será dado à cobertura jornalística do gênero informativo. ${ }^{8}$

Analisamos a narrativa jornalística para fazer reflexões sobre os discursos do jornalismo econômico. E isto implica uma distinção conceitual dos termos: discurso, narrativa jornalística e discurso jornalístico.

Bakhtin (1997) diz que a palavra discurso é usada para referir-se a vários significados:

Se refere indiferentemente à língua, ao processo da fala, ao enunciado, a uma seqüência (de comprimento variável de enunciados, a um gênero preciso do discurso, etc.), até agora, não foi transformada pelos lingüistas num termo rigorosamente definido e de significação restrita. 9

Adotamos o termo "discursos" como os conjuntos de formas verbais com as quais se pronunciam os meios de comunicação para seus leitores, suas fontes e seus anunciantes. Preferimos usar a palavra no plural para dar conta da idéia da sua multiplicidade (Pinto, 1999).

A diferença entre narrativa e discurso jornalístico pode ser estabelecida a partir das explicações do que os semiólogos chamam de pacto de leitura entre o diário e seus leitores, e que está relacionado com a identidade dos veículos de comunicação. Isto porque a leitura do jornal envolve uma "dupla identificação". O leitor reconhece o veículo jornalístico em meio à diversidade dos outros disponíveis no mercado e se identifica social e ideologicamente com ele (França, 1998).

8 O gênero informativo é aquele na qual a instituição jornalística assume o papel de observadora da realidade, registrando fatos e informando a sociedade. $\mathrm{O}$ estudo dos gêneros integra-se ao esforço de compreensão da propriedade discursiva. Age como ponto de partida para descrever e estudar as características da linguagem e permitir avanços na análise das relações que permeiam a totalidade do jornalismo. Ele se articula a partir de dois núcleos de interesse: a informação (saber o que se passa) e a opinião (saber o que se pensa sobre o que se passa). Um caminho que percorre a descrição dos fatos e a versão dos fatos - a reprodução do real e a leitura do real (Melo, 1994).

9 Em A estética da criação verbal, ele desenvolve uma abordagem sobre os gêneros do discurso, que seriam os tipos relativamente estáveis de enunciados elaborados por cada esfera de utilização da língua. São gerados a partir de uma dada função (científica, técnica, ideológica, oficial, cotidiana) e de condições específicas para cada uma das esferas da comunicação verbal. A estrutura da sociedade em classes introduz nos gêneros do discurso e nos estilos uma extraordinária diferenciação que se opera de acordo com o título, a posição, a categoria, a importância conferida pela fortuna privada ou pela notoriedade pública, pela idade do destinatário e, de modo correlato, de acordo com a situação do próprio locutor ou escritor (Bakhtin, 1997). 
No jornalismo, a sua manutenção, a continuidade da forma, a repetição do já conhecido servem como suporte, moldura, para o novo, o diverso, o que varia periodicamente. A vida de um veículo jornalístico se organiza, assim, nesse duplo movimento de opostos aparentes, em que um complementa e contextualiza o outro (Leal, 2002). Seguindo esse raciocínio, não há certamente a novidade absoluta nem a redundância excessiva, mas o novo é tornado visível a partir da repetição de fórmulas narrativas, colunistas, espaços, jornalistas e padrão visual. Ao mesmo tempo, a nova notícia promove o esvaecimento do já visto, do já conhecido no jornal.

Essa distância entre a história narrada e o suporte dessa narrativa, segundo ele (ibid.), é que permite a Landowski (1992), estudando o jornalismo diário, estabelecer uma distinção entre "narrativa" e "discurso" jornalístico.

A narrativa seria relativa aos "acontecimentos do dia" e envolveria uma temporalidade marcada pelo episódico, pela fragmentação e geradora de curiosidade, da expectativa pelo que "há de novo". O segundo, o discurso jornalístico, envolveria o advento do veículo, reconhecível em sua periodicidade. Assim, pode-se observar num veículo impresso, por exemplo, ao lado dos textos novos sobre fatos novos, uma série de marcas que indicam repetição, familiaridade e que o identificam como aquele jornal (Landowski, 1992). ${ }^{10}$

Estabelecendo essa diferença conceitual, reiteramos que o objetivo aqui é perceber na narrativa jornalística do jornal $O$ Globo não o seu discurso jornalístico,

\footnotetext{
10 O jornal, de acordo com Landowski (1992, p. 118-120), abre generosamente suas páginas ao aqui agora, à prospecção e à programação do vivido mais imediato dos seus leitores: rubricas de informações práticas, depoimentos, curiosidades, crônicas, correspondência dos próprios leitores, classificados e anúncios de todo tipo, programas audiovisuais, horóscopos, prognósticos e anúncios publicitários. Todos esses são espaços criados visando à manipulação dos estereótipos sociais que configuram a imagem de um sujeito normatizado por e para a própria recepção do discurso "midiático". Quantitativamente, tem-se um quarto, um terço, a metade do jornal, onde mais nada "acontece", mas em que se apresenta, em compensação, multiforme e coerente, um discurso de assunção e, primeiro, de construção do público leitor. Assim, em sua definição, um periódico é um "sujeito semiótico", uma entidade reconhecível socialmente. "Todos os leitores o sentem e muitas equipes redacionais trabalham nesse sentido: cada jornal tem seu estilo, um tom, um 'perfil' que o define e que faz dele uma figura social capaz de cristalizar duradouramente atitudes de atração e de repulsa.” Afinal, ao contrário de roupas e alimentos, que devem variar no cotidiano, o jornal, objeto de comunicação, solicita de cada indivíduo a compulsão inversa, exigindo a repetição, favorecendo o hábito ou a rotina, ou, mesmo disforicamente, uma certa constância como se, uma vez que alguém elegeu seu jornal, permanecer fiel a ele fosse, em suma, permanecer fiel a si mesmo (ibid.).
} 
que o caracteriza como um jornal específico dentro da imprensa brasileira e cria uma identificação com seu leitor (o pacto de leitura), mas os discursos da cobertura jornalística do campo econômico, ou seja, as vozes que falam nesses discursos.

A proposta é fazer uma abordagem sobre a narrativa jornalística do campo econômico à luz das reflexões bakhtiana e focaultiana sobre discursos. Mas ela não pode ser tratada como uma análise de total essência bakhtiana, como ele o fez no livro Problemas da poética de Dostoiévski (1930), na qual desenvolve uma análise teórico-literária da obra desse escritor russo ${ }^{11}$. Neste trabalho, não fazemos uma análise teórico-literária, mas uma análise dos discursos construídos pelo jornalismo sobre o campo econômico a partir da narrativa jornalística de $O$ Globo.

Esta abordagem também toma como aporte teórico a proposta de análise de discursos de Foucault, que trata da existência de uma "ordem de discurso", um conjunto ou série de tipos de discursos, definido socialmente, a partir de uma origem comum. São os discursos produzidos num mesmo contexto de uma instituição ou comunidade, para circulação interna ou externa e que interagem não apenas entre eles, mas também com textos de outras ordens discursivas.

"O discurso está na ordem das leis", afirma Foucault (2001, p 7). Para desenvolver sua reflexão, ele parte da hipótese de que em toda sociedade a produção do discurso é ao mesmo tempo controlada, selecionada, organizada e redistribuída por certo número de procedimentos que têm por função conjurar seus poderes e perigos, dominar seu acontecimento aleatório, esquivar sua pesada e temível materialidade.

E o que ele propõe como essencial para analisar os discursos? Foucault propõe uma análise das instâncias de controle discursivo e, para isso, diz ser necessária a observação de dois conjuntos: o crítico e o genealógico. O primeiro é o que põe em prática o princípio da inversão: procurar cercar as formas da exclusão, da limitação, da apropriação; mostrar como se formaram, para responder a que

\footnotetext{
${ }^{11}$ Nessa análise, Bakhtin tem como hipótese que Dostoiévski criou um tipo novo de pensamento artístico, a que chamou do tipo polifônico. Ele discute o romance polifônico de Dostoiévski e seu enfoque na crítica literária. E retoma sua idéia central - descrita no livro Marxismo e Filosofia da Linguagem - a que "tudo na vida é diálogo, ou seja, contraposição dialógica" (Bakhtin, 1995). A idéia central do pensamento dele é a idéia do outro, idéia de familiarização, do entendimento, do diálogo" (Bakhtin, 2004). E o romance polifônico, segundo ele, é inteiramente dialógico.
} 
necessidades, como se modificaram e se deslocaram, que força exerceram efetivamente, em que medida foram contornadas. Para ele, são três grandes sistemas de exclusão que atingem o discurso: a palavra proibida, a segregação da loucura e a vontade de verdade (ibid., p.19).

O outro conjunto, que Foucault chama de genealógico, é o que põe em prática três outros princípios - descontinuidade, especificidade e exterioridade - e questiona como séries de discursos se formaram, através, apesar, ou com o apoio desses sistemas de coerção; qual foi a norma específica de cada uma e quais foram suas condições de aparição, de crescimento, de variação (Foucalt, 2001, p. 60).

As descrições críticas e as descrições genealógicas devem alternar-se, apoiarse umas nas outras e se completarem. Para ele, a análise do discurso, assim entendida, não desvenda a universalidade de um sentido; ela "mostra à luz do dia o jogo da rarefação imposta, com um poder fundamental de afirmação”.

Assim, tendo como ponto de partida as perspectivas bakhtiana e foucaultiana, podemos avançar na reflexão sobre o jornalismo econômico e seus discursos.

\section{A construção do verdadeiro no campo econômico pelo noticiário}

E como podemos diferenciar o jornalismo econômico do jornalismo genérico? É importante fazer essa diferenciação quando se propõe fazer uma reflexão sobre os discursos dos meios de comunicação e a construção do verdadeiro - ou de verdades - no campo econômico.

Podemos dizer que no "jornalismo genérico" o objeto da informação é quase sempre o que foge às regras, uma anomalia, algo excepcional, e não a norma. As notícias nos informam sobre eventos singulares, descontinuidades, e não modelos e processos.

Já no jornalismo econômico, pelo fato de a economia ser muito mais um processo do que uma sucessão de fatos singulares, processos e sistemas são igualmente objetos de interesses, sendo singularizados pela linguagem jornalística, que os noticia como se fossem episódios. 
Mas na cobertura de economia, episódios e processos singulares precisam ser interpretados à luz de processos, leis ou relações econômicas, às vezes conflitantes. Essas relações são quase sempre ignoradas pelo senso comum, já que são formuladas em outro nível de saber: o saber das teorias econômicas (Kucinski, 2000).

E que ideologia perpassaria as práticas dessa área? De onde surgem seus padrões ideológicos? No jornalismo, normalmente, surgem dos modelos ideológicos dominantes em cada momento, que são os padrões das elites dominantes, conforme a tese consagrada de Marx em A Ideologia Alemã. Na ideologia do jornalismo econômico, especificamente, influem muito as teorias econômicas dominantes em cada período.

Os padrões ideológicos do jornalismo, oriundos dessas teorias, são moldados em boa parte pelos seis grandes jornais do mundo ocidental e pelas duas ou três revistas de circulação mundial: New York Times, Washington Post, Le Monde, The Guardian, Financial Times e The Wall Street Journal. Entre as revistas estão Times e The Economist (Kucinski, 2000, p. 184). No jornalismo econômico, The Economist ocupa posição-chave, como geradora primária de ideologia, papel que assumiu como proposta editorial e por ser a revista transnacional por excelência, que é lida pela comunidade internacional de homens de negócios.

O traço ideológico mais geral e permanente desses padrões tem sido o da defesa da livre empresa na esfera econômica e da democracia liberal na esfera da política. Apesar de proclamarem independência editorial e objetividade, é natural que ocorra com freqüência o colapso da objetividade nesses grandes veículos, especialmente durante as guerras e no tratamento das questões internacionais em geral, entre as quais economia.

Kucinski (2000) aponta como principais traços permanentes da ideologia do jornalismo econômico a escolha do capital e seu processo de acumulação - e não do homem - como objeto central de preocupação, o otimismo noticioso e o descaso com questões estruturais. 
A escolha do capital e não do homem como sujeito de sua história e objeto de suas preocupações decorre da ideologia de livre mercado em suas várias manifestações, desde o marginalismo ${ }^{12}$ até o neoliberalismo ${ }^{13}$.

A opção pela escolha da boa notícia, ao contrário do catastrofismo que caracteriza o jornalismo genérico, se justifica pela natureza do processo econômico, mas tem conotações ideológicas. A imprensa econômica abre seus melhores espaços a notícias consideradas positivas sobre o desempenho da economia e reluta em aceitar as adversidades econômicas.

Kucinski (ibid., p. 188) diz que no jornalismo econômico os ciclos expansivos sempre ganham uma sobrevida e as crises são em geral subestimadas. Destacar as crises seria admitir as disfunções do sistema. A propensão ao otimismo exagerado reflete também um ethos do empresariado em geral, que aposta nas oportunidades e prefere esquecer depressa as adversidades.

Esse subcampo do jornalismo seria, portanto, displicente no trato de problemas estruturais e crônicos, como a fome, o desemprego, a falta de habitação e transporte, as desigualdades mundiais, a desordem monetária internacional, como se isso tudo desafiasse seus fundamentos ideológicos (Kucinski, 2000, p. 188-189).

A difusão generalizada do jornalismo especializado em assuntos de economia na grande imprensa no Brasil está intimamente ligada à reorganização do capitalismo em escala mundial e ao seu desdobramento na economia brasileira a

\footnotetext{
12 Até a grande depressão nos anos 1930, os economistas diziam que toda economia tendia ao pleno emprego, e só não atingia devido a obstáculos colocados pelos próprios trabalhadores ao funcionamento regular do mercado. O culpado pelo desemprego era a própria vítima do desemprego, o trabalhador. O raciocínio básico subjacente a essa teoria é o de que sempre haverá emprego a um dado salário. Basta que o trabalhador aceite. Se não existissem sindicatos, que tornam os salários rígidos, haveria sempre pleno emprego, exceto o pequeno desemprego friccional (Kucinski, 2000, p. 134-135).

${ }_{13} \mathrm{O}$ neoliberalismo é uma doutrina político-econômica derivada dos princípios fundamentais do liberalismo. Suas bases foram lançadas em 1938, durante o Colóquio Walter Lippmann, com a pretensão de adotar o modelo liberal às novas condições do capitalismo no século XX. Um de seus princípios básicos é o monetarismo, que defende o controle da inflação mediante a redução das despesas do Estado e da redução salarial. O texto que deu origem a essa doutrina foi O caminho da servidão (1944) do economista austríaco Friedrich Hayek (18991992). O neoliberalismo defende a menor intervenção protecionista do Estado na economia, embora devam existir intervenções estatais para regular a ordem econômica de livre concorrência, evitando as tendências monopolísticas. Os dois maiores expoentes do neoliberalismo na política foram o ex-presidente norte-americano Ronald Regan e a exprimeira ministra britânica Margareth Thatcher (Alonso, 2000).
} 
partir da década de 1950. A prática da cobertura dessa área se fortalece no Brasil, principalmente, a partir do final da década de 1960, se identificando com o modelo de desenvolvimento econômico do país (Quintão, 1987).

Como gerador dos discursos sobre o campo econômico, o jornalismo econômico teve um papel importante na campanha neoliberal dos anos 1990 pelo desmonte do Estado social-democrata. Teve e tem uma participação crucial no processo de naturalização da ideologia neoliberal que se fortaleceu, nas últimas décadas do século XX, com o colapso da economia soviética, planificada e estatal. A tese da ideologia neoliberal sacrifica o princípio da solidariedade social sob o argumento de uma suposta eficiência econômica.

Como ideologia dominante, encampada pela cobertura jornalística da área econômica, a tese da globalização legitimou a ocupação de novos espaços pelo capital financeiro mundial, especialmente nos países periféricos, sob o argumento de que se trata de um desenvolvimento natural das forças produtivas - visão compartilhada por diversos autores, como Kucinski (2000), Sodré (2002) e Moraes (2003).

\section{Uma cobertura polifônica do campo econômico}

Ao analisar as edições de $O$ Globo, observamos que as notícias podem ser classificadas em três categorias mais amplas de discursos. A primeira engloba as notícias em que predomina o discurso oficial sobre os fatos. Na segunda há predominância do discurso de agentes do mercado. E a outra é aquela em que a cobertura se dá pela repercussão dos fatos junto ao mercado e ao(s) consumidor (es).

Nas matérias da primeira categoria, como o próprio nome diz, predomina a voz das fontes oficiais. Falam e defendem o Plano Real o presidente, ministros e diretores do Banco Central da época de lançamento desse pacote econômico.

As primeiras medidas de estabilização da economia que levam ao Plano Real são tomadas em 1993. Em $1^{0}$ de julho de 1994, o ministro da Fazenda, Fernando Henrique Cardoso (FHC), do governo Itamar Franco, lança esse pacote econômico, 
que busca obter a estabilização sem usar recursos como o congelamento de preços e salário - medidas de planos anteriores. ${ }^{14}$

Na edição de $O$ Globo desta data, encontramos o presidente da época conclamando o povo a ajudar o novo plano a dar certo. É o que observamos na narrativa jornalística com o título Itamar pede ajuda popular para garantir êxito do Real, retranca principal que leva como sub-retranca o discurso, na íntegra, do presidente, com o título $O$ real é conquista do povo. ${ }^{15}$

Outra voz oficial que fazia a defesa do plano e o utilizou largamente como uma plataforma para ser eleito presidente da República foi FHC. No dia $1^{\mathrm{o}}$ de julho de 1994, já afastado do cargo de ministro e se apresentando como candidato do PSDB à presidência, FHC dá uma entrevista pingue-pongue para $O$ Globo com o título $F H C$ - pacote para reorganizar o estado. As esferas política e econômica se misturam nessa narrativa, pois o candidato ao mais importante cargo público do país fala do Plano Real e se coloca como o pai do pacote.

Sobre esse aspecto, Kucinski (2000, p. 129) lembra que o Plano Real foi concebido com o objetivo central de vencer a eleição presidencial, sendo cronometrado para produzir o máximo de efeitos benéficos às vésperas das eleições, incluindo uma espetacular troca de moeda. ${ }^{16}$

\footnotetext{
${ }_{14}$ As medidas do Plano Real visam a conter gastos públicos, acelerar o processo de privatização das estatais, controlar a demanda por meio da elevação de juros e pressionar os preços pela facilitação das importações. A moeda, que havia mudado de cruzeiro para cruzeiro real em agosto de 1993, muda para real em julho de 1994. O programa prevê continuação da abertura econômica do país e medidas de apoio à modernização das empresas brasileiras. Durante o governo de FHC, que toma posse como presidente em 1995, o Plano Real continua apresentando bons resultados quanto ao combate à inflação (Planos Econômicos, 2004). ${ }_{15}$ No jargão jornalístico, retranca é a matéria principal da página e sub-retranca é uma matéria secundária ligada à retranca principal.

16 O potencial eleitoral dos planos de estabilização já havia sido demonstrado na Bolívia e na Argentina. Em ambos os países, o eleitorado, aliviado de imediato por uma estabilização de preços, mudou radicalmente sua postura eleitoral. O Plano Real inspirou-se no chamado "consenso de Washington", um projeto de reestruturação econômica dos países latinoamericanos, apoiado pelo governo norte-americano, que propõe privatizações aceleradas e utiliza a dolarização e a redução das tarifas de importação como meios de estabilização monetária. Isso foi feito atribuindo a uma URV um poder de compra diferente todos os dias de manhã. Em seguida, após um período de estímulo ao alinhamento dos preços, foi introduzido o real, de valor igual à URV, e um congelamento dos salários e das tarifas públicas. Esse congelamento e a entrada mais barata de produtos estrangeiros em URV asseguraram um grau de estabilidade nos preços dos bens que não tinham oferta internacional (Kucinski, 2000, p. 129-130).
} 
A predominância das vozes oficiais (ou fontes oficias no jargão jornalístico) aparece em quase todas as edições analisadas. Pensar as vozes que falam no noticiário de economia nos remete ao conceito de polifonia de Bakhtin ${ }^{17}$ e revela o que podemos chamar de uma cobertura polifônica do campo econômico. Aliás, podemos dizer que, no jornalismo, uma regra da deontologia da profissão que persegue a manutenção da polifonia na narrativa jornalística é a objetividade. ${ }^{18}$

Na cobertura de economia, as fontes de informação são principalmente as oficiais e os especialistas, no caso os economistas, operadores de mercado, empresários e profissionais da área de finanças. Elas disputam o espaço das páginas dos jornais na construção dos discursos sobre o campo econômico e são as vozes que têm mais força - mais visibilidade - nesta cobertura. De um lado, o governo, representando pelo presidente da República, ministros e representantes do Banco Central (uma das autoridades monetárias do país e responsável por executar a política financeira do governo), e falam quase sempre de forma positiva sobre as ações do governo.

\footnotetext{
${ }^{17}$ Em lingüística, polifonia é, para Bakhtin, a presença de outros textos dentro de um texto, causado pela inserção do autor num contexto que já inclui previamente textos anteriores que lhe inspiram ou influenciam. A polifonia é um fenômeno também identificado como heterogeneidade enunciativa, que pode ser mostrada (no caso de citações de outros autores em obras acadêmicas, por exemplo) ou constitutiva (como a influência de dramaturgos clássicos em Shakespeare, por exemplo, que não é mencionada diretamente, mas transparecida).

${ }^{18}$ A objetividade no jornalismo não é a negação da subjetividade, mas uma série de procedimentos que os membros da comunidade interpretativa utilizam para assegurar uma credibilidade como parte não-interessada e se protegerem contra eventuais críticas ao seu trabalho. Gaye Tuchman afirma que a objetividade pode ser vista como um ritual estratégico que serve para proteger os jornalistas dos riscos da sua profissão. Os jornalistas têm de ser capazes de invocar algum conceito de objetividade a fim de trabalhar os fatos relativos à realidade social. Ela afirma que os jornalistas utilizam procedimentos para a produção da notícia, que são exemplificados como atributos formais das notícias e dos jornais, que são efetivamente estratégias através das quais os jornalistas se protegem dos críticos e reivindicam, de forma profissional, a objetividade. Eles podem afirmar que: apresentaram versões diferentes de uma mesma realidade; apresentaram provas suplementares para fundamentar um fato; utilizaram aspas para indicar que o repórter não está dando uma versão dos acontecimentos; apresentaram os fatos mais importantes primeiro (o uso da pirâmide invertida); e separaram cuidadosamente os fatos das opiniões através da utilização do rótulo de notícia de análise. Os jornais deixam claro para o leitor os espaços destinados aos gêneros opinativos - editoriais, artigos, colunas e críticas (Tuchman, 1993).
} 
De outro lado, estão os especialistas do campo econômico, que fazem análise com base em um conhecimento específico e que, muitas vezes, aparecem representando o mercado, uma grande entidade que congrega várias vozes.

A retranca principal da editoria de economia da edição do dia 4 de julho de 1994 traz um exemplo de uso desse termo pelos meios de comunicação como uma grande voz formada por múltiplas vozes: Mercado deverá abrir hoje com juros nominais de até $8 \%$.

Em sentido geral, o termo mercado designa um grupo de compradores e vendedores que estão em contato suficientemente próximo para que as trocas entre eles afetem as condições de compra e venda dos demais. Um mercado existe quando compradores que pretendem trocar dinheiro por bens e serviço estão em contato com vendedores desses mesmos bens e serviços. Ele pode ser entendido como o local, teórico ou não, do encontro regular entre compradores e vendedores de uma determinada economia. Concretamente, o mercado é formado pelo conjunto de instituições em que são realizadas transações comerciais (feiras, lojas, Bolsas de Valores ou de Mercadorias, etc.) e se expressa sobretudo na maneira como se organizam as trocas realizadas em determinado universo por indivíduos, empresas e governos (Sandroni, 2005). ${ }^{19}$

As outras vozes que aparecem no noticiário sobre o campo econômico são os consumidores, representantes do povo que têm um papel determinante numa economia de mercado, em relação à compra e venda de bens e serviços, de acordo com o princípio de soberania do consumidor ${ }^{20}$. Um exemplo deste aspecto pode ser

\footnotetext{
${ }^{19}$ A formação e o desenvolvimento de um mercado pressupõem a existência de um excedente econômico intercambiável e, portanto, de certo grau de divisão e especialização do trabalho. Historicamente, isso ocorre nas cidades européias no final da Idade Média. Com a formação regular do excedente, a antiga economia natural ou de subsistência passa a ser substituída por um mecanismo de mercado, que é formado basicamente pela oferta de bens e serviços e pela demanda (ou procura) desses bens e serviços. Da interação desses elementos surge um sistema de preços que vai orientar a economia no sentido do aumento ou da redução da produção (Sandroni, 2005, p. 528-529).

${ }^{20}$ Este princípio coloca o consumidor como a peça-chave do mercado e também o elemento orientador do que é preciso produzir, limitando-se o produtor a seguir seus desejos e necessidades. Na prática, essa soberania tende a ser neutralizada pelos mecanismos impositivos da concorrência monopolista e pela influência da publicidade. E, afinal, é o nível de renda dos consumidores que determina objetivamente os limites dessa soberania (Sandroni, ibid., p. 182).
} 
encontrado na edição do dia 31 de julho de 1994, em uma matéria com o título: Reação do consumidor determina preços.

E é para orientação do consumidor que parte da cobertura jornalística de economia voltada para a prestação de serviços é direcionada. Ele é ouvido mais como um termômetro da recepção do plano econômico pela população. Um exemplo dessa característica está na matéria É hora de organizar a vida com a nova moeda, seguida de dois boxes - O que muda no bolso com a nova moeda e Os cuidados nas compras a prazo - na edição do dia 3 de julho.

Essa tentativa de desenvolver um jornalismo de orientação ao consumidorleitor e, portanto, de prestação de serviços, é uma das mudanças verificadas nessa cobertura. Ao refletir sobre as transformações do jornalismo econômico para se adaptar à conjuntura mundial do final do século XX, verificam-se três momentos importantes: passa de um jornalismo que servia ao regime militar fazendo propaganda econômica do governo para um "jornalismo pedagógico" e voltado para os cidadãos nos anos 1980 e, na década seguinte, a serviço da economia virtual e do mercado.

A abordagem dessa cobertura como jornalismo pedagógico foi desenvolvida em um trabalho anterior (Lene, 2005), mas algumas de suas características devem ser citadas aqui ao citarmos a voz do consumidor nesse noticiário. Observa-se que, depois da redemocratização do Brasil, em 1985, com a eleição de Tancredo Neves à presidência e, sobretudo, ao longo do traumático processo de tentar estabilizar a moeda, que tomou os dez anos seguintes, a imprensa econômica vai se especializando cada vez mais.

Basile (2002, p. 75) explica que isso era necessário para que o público entendesse a complexidade das questões envolvidas nas tentativas de proceder à estabilização da moeda; entender como e por que o Brasil tinha quebrado, nos idos de 1981; quais as novas condições da retomada do crescimento e, sobretudo, por que o país era uma nação tão injustamente dividida entre ricos e pobres.

A democratização foi também um movimento de ampliação do espaço da imprensa econômica de maneira geral. As redes de televisão, que pouco espaço davam à economia, passaram a preocupar-se seriamente com o tema. Publicações 
segmentadas como newsletters e revistas especializadas para cada setor de atividade econômica começaram a surgir (Basile, 2002).

Assim, com os repetidos pacotes econômicos implementados a partir da década de 1980, tornou-se vital no cotidiano das pessoas o jornalismo de serviços. A implementação dos diferentes planos mexia com o cotidiano. E a partir dessa sucessão de pacotes podemos dizer que foram ficando claras duas funções que o jornalismo econômico assumiu diante desses eventos: noticiar (e antecipar os fatos e dar furos) e informar pessoas e empresas sobre os caminhos do dinheiro. ${ }^{21}$

Um dos eventos da história recente do país que teve importância para o crescimento da imprensa econômica foi o confisco da poupança empreendido pelo presidente Fernando Collor de Mello em 1990. Explicar as conseqüências desse plano para os cidadãos foi uma oportunidade para os veículos. Investiu-se muito na cobertura econômica e de negócios e, sobretudo, na explicação dos vetores que afetam as finanças das pessoas. Os jornais diários passaram a abrir seções de finanças pessoais para seus leitores e novos canais de comunicação começaram a se estabelecer com o público.

Na década de 1990, a imprensa econômica vai valorizar ainda o uso de matérias acompanhadas de tabelas, gráficos e infográficos para tornar ainda mais pedagógica a notícia de economia e para acompanhar os novos hábitos de um leitor

\footnotetext{
${ }^{21}$ Kucinski (200o, p. 16) registra que o jornalismo de serviços vai se expandir a partir dos desdobramentos da crise do "milagre econômico" primeiro, com a alta do petróleo; depois, com as greves operárias, e a profunda recessão dos anos 1980; e finalmente a alta dos preços. A inflação vai alimentar esse tipo de jornalismo, voltado aos problemas econômicos e financeiros de seus leitores de classe média, tais como prestações da casa própria, aplicações em poupança, impostos e taxas escolares, custo de vida e defesa do consumidor. Apesar de reforçar a ideologia do consumismo junto às classes médias, trata-se de um jornalismo que, de certa maneira, tenta recolocar o cidadão como sujeito da história e objeto da preocupação jornalística.
} 
que também vai buscar notícias econômicas na Internet ${ }^{22}$. Essa foi a época da informatização das redações. ${ }^{23}$

\section{Um exercício de futurologia: verdades e falácias dos discursos da economia}

Com o advento das novas tecnologias da informação e da comunicação e aumento da velocidade da informação o jornalismo econômico foi ganhando importância. Ele vai servir cada vez mais à economia virtual porque os fluxos de informação são tão rápidos, abundantes e vigorosos que passado e futuro passaram a ficar comprimidos em percepções sintetizadas no presente. No mundo de hoje, os mercados financeiros fazem a mediação entre as percepções sobre o futuro, a soma dos diagnósticos e de prognósticos.

Uma das características dos discursos do jornalismo econômico que podem ser observadas - e é uma das mais marcantes - é o constante tratamento como verdade de prognósticos.

A cobertura jornalística do campo econômico é muito mais construída em torno de análises, estimativas, especulações, aproximações e pontos de vistas sobre cenários futuros de fontes especializadas do que por fatos concretos. Há vários exemplos nas edições analisadas. A título de exemplificar essa característica, citamos uma matéria da edição do dia 10 de julho de 1994. O antetítulo da matéria era Chegada do real promete mudar cenário da lucratividade do país e o título $O$ sobee-desce do lucro em tempo de nova moeda.

Um outro exemplo de matéria construída a partir de análises sobre cenários pode ser encontrado na edição de 31 de julho de 1994, com matérias de repercussão sobre o primeiro mês de vigência do Plano Real. Os títulos das matérias principais da

\footnotetext{
22 A rede mundial de computadores chegou ao Brasil como Internet comercial na década de 1990 e o impacto de uma nova mídia eletrônica gerou a adoção de dois conceitos que pautam hoje o planejamento das empresas de comunicação: a produção de conteúdo independente do meio, que leva os conglomerados de comunicação a reaproveitar o mesmo material em diversas mídias e produtos, e a possibilidade de convergência dos meios que operam hoje de modo independente, como a televisão, o rádio e a Internet.

23 De 1986 a 1990 os principais jornais brasileiros instalam na redação e na área dos classificados sistemas integrados de computadores. Até 1990 o jornalismo impresso fez investimentos de US $\$ 100$ milhões em novas tecnologias, conforme estimativa da Associação Nacional de Jornais. Isto representou, "a maior revolução industrial da imprensa brasileira em todos os tempos" (Bahia, 1990).
} 
editoria de economia foram: Plano deixa o mercado otimista e real passa no teste do primeiro mês (com o boxe Economistas analisam o primeiro mês do real). ${ }^{24}$

Aliás, sobre a construção de cenários pelas fontes especializadas é importante acrescentar que, em geral, elas o fazem a partir de suas expectativas com relação ao desempenho da economia, quase sempre positivas. Analisar de forma negativa pode fazer com que setores deixem de lucrar, e a possibilidade contínua de se obter lucro é a mola que move o capitalismo e seus discursos. Também ocorrem interpretações de dados sobre desempenho da economia do país a partir de projeções das fontes especializadas sobre medidas que elas acham que o governo deveria adotar.

Outro ponto importante que a análise das edições indica na cobertura econômica e que também está relacionado com a interpretação por parte das fontes é o uso das estatísticas na pauta do jornalismo. Kucinski (2000) ressalta que, no debate econômico, abusa-se das falácias, argumentos com premissas aparentemente corretas, mas cujas conclusões são falsas. E a mais freqüente é a falácia estatística.

Quase tudo pode ser provado em economia, manipulando-se estatísticas. Escolhem-se dois pontos convenientes de uma série estatística para provar, por exemplo, que os preços agrícolas sofreram uma perda em seu poder de troca. Poderiam ser escolhidos outros dois pontos, não muito distantes, para se provar exatamente o contrário.

Esses aspectos mostram que na economia o que é verdade para um agente econômico pode ser falso para o conjunto dos agentes econômicos. Freqüentemente, jornalistas e economistas formulam leis gerais, e, portanto, relações de causalidade, com base em observações singulares. O que é um risco e um erro metodológico. Observações singulares, como ressalta Kucinski (2000, p. 25), não garantem a validade de uma lei geral.

É comum, no debate econômico, o recurso ora sincero ora retórico a teses já refutadas. Para escapar das falsas relações de causalidade, ou da formulação de leis inválidas, Kucinski (ibid.) afirma que o jornalista deve evitar generalizações e tomar

24 No boxe, O Globo ouviu economistas brasileiros de renome no país, como Mário Henrique Simosen, Maria da Conceição Tavares, João Paulo dos Reis Velloso, Roberto Campos, Dionísio Carneiro, Paul Singer, Daniel Dantas e Affonso Celso Pastores. 
cuidado com a validade de suas premissas. Na lógica dedutiva, se as premissas forem verdadeiras, a conclusão tem de ser verdadeira. Em economia deve-se preferir a lógica indutiva, que trata da maior ou menor probabilidade de uma conclusão ser verdadeira.

Assim, o jornalismo, como gerador dos discursos sobre o campo econômico, serve para informar, mas muitas vezes endossa como verdades anúncios sobre o futuro. No caso específico da cobertura do Plano Real, verificamos o endosso por parte do veículo de comunicação e dos jornalistas das informações passadas pelas fontes oficiais, ou seja, a explicitação em várias matérias de que o plano realmente daria fim à inflação. Um exemplo disso está na edição do dia do lançamento do Plano Real, na matéria $B C$ só poderá emitir $r \$ 9,5$ bi até março de 95. O lead começava afirmando que as medidas dariam certo: "A moeda que trará a estabilidade da economia brasileira terá um controle rígido". (grifo nosso).

Nota-se, neste caso, que o uso do verbo no tempo futuro dá sentido positivo com relação aos resultados que ainda poderiam ou não ser alcançados pelo novo pacote.

\section{Considerações finais}

A proposta deste artigo foi articular a construção do verdadeiro no campo econômico e os discursos dos meios de comunicação sobre esta área. A questão central que se colocou nesta reflexão foi: como as notícias ajudam a construir uma "realidade" sobre o campo econômico?

A análise - desenvolvida a partir de um corpus composto por edições do jornal $O$ Globo de julho de 1994, mês de lançamento do Plano Real, e das reflexões sobre a questão da comunicação e do discurso de autores como Mikhail Bakhtin e de Michel Foucault e de outros aportes teóricos - nos permitiu apontar alguns aspectos dos discursos produzidos pelos meios de comunicação na cobertura de economia.

De forma resumida, identificamos que o noticiário econômico se pauta, principalmente, pelos prognósticos e não apenas pelos relatos de acontecimentos do presente. Com isso, muitas vezes, antecipam situações, constroem cenários futuros como verdades do presente, e, conseqüentemente, provocam mudanças em um 
mercado onde as operações são cada vez mais virtuais, voláteis, e cujas decisões são fortemente influenciadas pelos discursos sobre os rumos dos setores da economia.

Assim, a construção de verdade sobre o campo econômico pelos meios de comunicação passa por especulações sobre as medidas tomadas pela política monetária do governo, por aproximações, estimativas e cenários futuros desenhados por fontes especializadas no campo econômico, o que pode levar a informações equivocadas dependendo da interpretação que se dá ao assunto.

Há predominância de vozes (ou fontes) oficiais nesse noticiário. O mercado é tratado como uma grande entidade que congrega múltiplas vozes e os meios de comunicação tentam traduzir os fatos econômicos e orientar o consumidor sobre as mudanças em curso na economia. Muitas vezes, endossam os discursos das vozes de forma excessivamente positiva. Verifica-se na narrativa jornalística a presença de uma linguagem hermética - com termos técnicos -, mas que tenta ser pedagógica para o leitor.

\section{Referências Bibliográficas}

ALONSO, J. A. M. 2000. Dicionário de História do Mundo Contemporâneo. Vitória Espírito Santo: Instituto Histórico e Geográfico do Espírito Santo (IHGES).

BAHIA, Juarez. 1990. Jornal, história e técnica: história da imprensa brasileira. São Paulo: Editora Ática S.A., v.o1.

BAKHTIN, Mikhail. 1995. Marxismo e filosofia da linguagem. São Paulo: Editora Hucitec. 1997. Os gêneros do discurso. In: (Ed.). Estética da criação verbal. São Paulo: Martins Fontes, p.277-926. . 2004. Problemas da poética de Dostoievski. São Paulo: Hucitec.

BARBOSA, Marialva. 2000. Os donos do Rio - imprensa, poder e público. Rio de Janeiro: Vício de Leitura.

BASILE, Sidney. 2002. Elementos do jornalismo econômico. Rio de Janeiro: Campus.

FOUCAULT, Michel . 2001. A ordem do discurso - aula inaugural no Collège de France, pronunciada em 2 de dezembro de 1970. São Paulo: Edições Loyola.. . 2005. Vigiar e Punir - o nascimento da prisão. Petrópolis: Editora Vozes. 
FRANÇA, Vera. 1998. Jornalismo e vida social: a história amena de um jornal mineiro. Belo Horizonte: Editora da UFMG.

KUCINSKI, Bernardo. 2000. Jornalismo econômico. São Paulo: Editora da Universidade de São Paulo.

LANDOWSKI, Eric. 1992. A sociedade refletida. São Paulo: Educ/Pontes.

LEAL, B. D. S. 2002. A produção da familiaridade e o pacto de leitura jornalístico. In: INTERCOM - Sociedade Brasileira de Estudos Interdisciplinares da Comunicação - Anais do XXV Congresso Brasileiro de Ciências da Comunicação. Salvador - BA: $1^{\circ}$ a 5 de setembro de 2002. LENE, Hérica. O consumo como agente modificador da imprensa econômica no final do século XX: rumo a um "jornalismo pedagógico". In: INTERCOM - Sociedade Brasileira dos Estudos Interdisciplinares da Comunicação - Anais do XXVIII Congresso Brasileiro de Ciências da Comunicação, Rio de Janeiro: 5 a 9 de setembro de 2005.

MCCHESNEY, R. W. 2003. Mídia global, neoliberalismo e imperialismo. In: MORAES, Dênis. (Org.). Por uma outra comunicação - Mídia, mundialização cultural e poder. Rio de Janeiro - São Paulo: Editora Record.

MELO, J. M. D. 1994. A opinião no jornalismo brasileiro. Petrópolis: Editora Vozes.

MORAES, Denis de. 2003. O capital da mídia na lógica da globalização. In: MORAES, Dênis de (org.). Por uma outra comunicação - mídia, mundialização cultural e poder. Rio de Janeiro - São Paulo: Editora Record.

PINTO, Milton José. 1999. Comunicação \& Discurso: introdução à análise de discursos. São Paulo: Hacker Editores.

PLANOS ECONÔMICOS. 2004. In: ALMANAQUE ABRIL 2004. São Paulo: Editora Abril.

QUINTÃO, Aylê-Salassiê Figueiras.1987. O jornalismo econômico no Brasil depois de 1964. Rio de Janeiro: Editora Agir.

SANDRONI, Paulo. 2005. Dicionário de economia do século XXI. Rio de Janeiro e São Paulo: Record.

SODRÉ, Muniz. 2002. Antropológica do espelho. Petrópolis - Rio de Janeiro: Editora Vozes.

SODRÉ, Nelson Werneck. 1999. História da Imprensa no Brasil. Rio de Janeiro: Mauad.

THOMPSON, John B. 2002. A mídia e a modernidade - uma teoria social da mídia. Petrópolis, RJ: Editora Vozes.

TUCHMAN, Gaye. 1993. A objectividade como ritual estratégico: uma análise das noções de objectividade dos jornalistas. In: N. Traquina (Ed.). Jornalismo: questões, teorias e "estórias". Lisboa: Veja., p.74-90. 